\title{
Characterisation of Spheroidised tungsten carbide metco 32c powder using radio frequency plasma
}

\author{
RM Dire', H Bissett ${ }^{2}$, D Delport ${ }^{1}$, K Premlall' \\ ${ }^{1}$ Tshwane University of Technology, Staatsartillerie Road, Pretoria West, Pretoria, 0183, South Africa \\ ${ }^{2}$ The South African Nuclear Energy Corporation SOC Ltd. (Necsa), Elias Motsoaledi Street Extension (Church Street West)R104 Pelindaba, \\ Madibeng Municipality, North West Province, 0240, South Africa \\ Email: rearabetswedire@gmail.com, Hertzog.bissett@necsa.co.za, premlallk@tut.ac.za,DelportD@tut.ac.za
}

\begin{abstract}
Metco 32C is a coarse grey powder, which mostly consists of tungsten carbide and cobalt; with small traces of nickel, chromium, boron, iron silicon and carbon. Metco 32C powder has the role of supporting oxidation and corrosion resistance at high temperatures as well as increasing the hardness of the coated materials.

The spheroidal morphology of Metco 32C improves flowability during layer application methods such thermal spraying. There has been a growing interest in the development / improvement of methods producing powders of cast tungsten carbide and other high-melting-point materials of uniform composition, characterised by a high sphericity of the particles and having higher physicalmechanical properties. Spherical particles are generally preferred in the additive manufacturing process as they pack together for uniform powder bed density, better flowability in machinery, eliminate internal cavities and fractures resulting in a better quality of final product. Similarly, thermal spraying processes also require dense, spherical particles to ensure consistency and reproducibility of the feeding mechanism as well as interaction between the feedstock and thermal spraying heat source. The process of transforming irregularly shaped powder particles into spherical shapes is known as the spheroidisation process and this can be achieved by plasma spheroidisation.

It was found that the spheroidisation ratio of the powder increased as the plasma plate power increased. A decrease in density was observed as plasma power increased. The spheroidised powders have a smaller particle size distribution (PSD) than the feed powders (un-spheroidised). The XRD results showed that as the plasma plate power increased the $\mathrm{WC}$ phase composition decreased, subsequently the phase composition of $\mathrm{W}_{2} \mathrm{C}$ increased.
\end{abstract}

Keywords: Tungsten carbide, Metco 32C powder, Spheroidisation, Radio frequency plasma

\section{Introduction}

Tungsten carbide Metco $32 \mathrm{C}$ is a brand name of a form of a self-fluxing alloy which has a hard phase constituent of tungsten carbide. These blends undertake the role of supporting oxidation and corrosion resistance at high temperatures as well as increasing the hardness of the coated materials (Oerlikon, 2017).

Metco $32 \mathrm{C}$ has the highest concentration of tungsten carbide as opposed to other self-fluxing alloys. Metco 32C powder which has high wear resistance depicts great characteristics for post-coat fuse for dense, virtually porosity free, metallurgical bonded coatings (Oerlikon, 2017). Carbide particles are usually 'cemented' by a binder metal, such as cobalt, which liquidizes during the sintering process and acts as a glue which bonds the tungsten carbide particles. Cemented carbides using tungsten carbide (WC) as the main raw material usually depict characteristics of high hardness and excellent wear resistance and are widely used in drills, moulds, needles, cutting tools, and other special processing industries as coatings on these materials. Due to the high bonding strength and fine microstructure between ultrafine tungsten carbide particles and metal binder phase, ultrafine-grain cemented carbide combines the characteristics of ceramics and metal at the same time, which has high toughness, good strength and excellent hardness (Yu-Cheng, et al., 2020).

Additive manufacturing (AM) is a fast growing technology in which a shape/object is fabricated using layer-by-layer deposition of a material, in a bottom-up manufacturing operation (Wohler, 2014). AM allows manufactures to produce components which are more cost- and resource efficient on a small scale production (Neely, 2008), due to this technologies value chains are shorter, more localised, more collaborative, and offer significant sustainability benefits (Gebler, et al., 2014).

The most important powder characteristics to consider for AM include: particle size, shape, flow, density, porosity, surface area and topography which includes characterisation methods such as light scattering and image analysis (such as SEM and optical microscopy) for particle sizes and particle size distribution (PSD) determination, Energy Dispersive Spectroscopy (EDS) for surface characterisation and a Hall flow for the flowability measurements of the powder (Committee, 2020). Although not a ascribe standards method for powder surface characterisation, X-ray diffraction (XRD) is employed to determine the crystal structure of phases within the powder particles. (Sutton, et al., 2016.). 
Powder spheroidisation is the process of transformation of either agglomerated/ irregular shaped powder into spherical powder particles. Radio frequency (RF) induction plasma technology can be used to achieve this through in-flight heating and melting of feed material particles followed by rapid cooling and solidification under controlled conditions. The material melts and is reformed into spherical particles (Wahll, et al., 2014).

Spherical powders can cater to a wide range of applications such as hard surfacing, cold spray, thermal spray, metal injection moulding and additive manufacturing (Hendrixson, 2016). To achieve optimum flow characteristics and high packing density, an ideal AM metal powder should be highly spherical in shape with no satellites (finer particles). Increased particle sphericity can improve powder feeding, resulting in smoother layers, improved packing density, increased heat conduction in the powder bed and an enhanced melting profile (Wahll, et al., 2014).

RF plasma spheroidisation, is the method available for the production of spherical tungsten powders due to the high melting point of this material (Haehn, et al., 1986). (Lu, et al., 2012) (Tong, et al., 2015). RF plasma can achieve temperature of $10,000 \mathrm{~K}$ or higher (Guo, et al., 2010).

Entities such as the National Laser Centre (NLC) at the Council for Scientific and Industrial Research (CSIR) uses WC for thermal coating purposes on various materials. Methods such as thermal spraying requires spherical particles to ensure effective splat formation on the substrate or surface being coated.

The focus of this study was to spheroidise irregularly shaped tungsten carbide Metco 32C powders to at various plate powers (power supply of the ICP torch into the plate current) making use of the $15 \mathrm{~kW}$ Tekna plasma spheroidisation system and to characterise the powder according to the additive manufacturing requirements.

\section{Experimental}

The as-received Metco 32C tungsten carbide powder was sieved into various fractions using a sieve shaker. Only the sieve fraction 63-90 $\mu \mathrm{m}$ was used for this study because this size fraction accounted for $81 \%$ of the entire sample.

\subsection{Spheroidisation ratio, fraction of evaporation, particle density and particle size distribution}

A schematic representation of the Tekna $15 \mathrm{~kW}$ induction plasma system which is situated at the South African Nuclear Energy Corporation (Necsa) is shown in Figure 1. Additional detail regarding the inductively coupled plasma (ICP) torch design describing the plasma gas, sheath gas, feeding probe and torch wall can be found in literature (Bissett \& Walt, 2017). The powder is introduced into the feeding probe via a vibration feeder and swept into the ICP torch by the carrier gas. For the purpose of this study the plasma torch was mounted onto a reactor chamber equipped with a catch-pot for the collection of the solid particles. During plasma treatment evaporation of the particles might occur, resulting in the formation of fine deposits which will be collected at the bottom of the cyclone and the filter. The tungsten carbide powder was treated at various conditions as indicated in Table 1. For all experiments the powder feed rate was approximately 0.7



Figure 1: Schematic of powder spheroidisation process in a radio frequency plasma

$\mathrm{kg} / \mathrm{h}$, reactor pressure $85 \mathrm{kPa}$ (abs) and the carrier gas (Ar) flow rate was 2 standard litres per minute (slpm). After spheroidisation the collected powders were weighed in order to determine what fraction of the powder evaporated (condensed as very fine particles of $<<150 \mathrm{~nm}$ ).

Table 1 shows the conditions at which the Metco 32C powder particles were spheroidised at. The energy consumption is a function of power and the rate at which the powder was fed at into the plasma using a vibration feeder set at pre-calibrated settings. Helium was introduced into the sheath gas to protect the torch wall and to assist in energy transfer from the plasma to the powder particles.

Table 1: Thermal plasma conditions for the treatment of WC powder size 63-90 $\mu \mathrm{m}$ and with Helium (He) as the sheath gas at a concentration of $0.67 \% \mathrm{v} / \mathrm{v}$

\begin{tabular}{cc}
\hline Plasma plate power $(\mathbf{k W})$ & $\begin{array}{c}\text { Energy consumption } \\
(\mathbf{k W . h} / \mathbf{~ k g})\end{array}$ \\
\hline 10 & 4.37 \\
12 & 4.7 \\
15 & 12.4 \\
\hline
\end{tabular}

Scanning electron microscopy (SEM) analyses of the treated/ densified powders were performed using a Quanta FEI 200 D SEM system. Image processing was applied on the Back-Scattered Electron (BSE) images as obtained from the SEM. The Carl Zeiss Zen 2 Core software package was used to determine if there was a quantifiable change in the particle morphology under different conditions. The average circularity was determined by evaluating a number of particles and making use of Equation 1. The shape factor $f_{\text {circ }}$ is the circularity, a function of the perimeter $P$ and the area $A$ of the particle:

$$
f_{\text {circ }}=\frac{4 \pi A}{P^{2}}
$$

In this instance the circularity varies between 1 and approaching 0 , with the circularity of a circle equal to 1 .

The feed and the plasma-treated powders were also characterised according to density, using an AccuPyc II 1340 gas displacement 
Table 2: Tekna plasma conditions and results for spheroidisation of tungsten carbide Metco 32C powder

\begin{tabular}{cccccccc}
\hline $\begin{array}{c}\text { Plasma plate } \\
\text { power (kW) }\end{array}$ & $\begin{array}{c}\text { Sheath gas composition } \\
\text { (Ar/-) slpm }\end{array}$ & Powder fed (g) & Feed rate (kg/h) & Catch pot (g) & Cyclone (g) & Evaporated (\%) \\
\hline 10 & $\operatorname{Ar}(14) / \mathrm{He}(30)$ & 27.34 & 2.29 & 26.96 & 0.38 & 1.3 \\
12 & $\operatorname{Ar}(14) / \mathrm{He}(30)$ & 28.19 & 2.54 & 27.84 & 0.35 & 1.6 \\
15 & $\operatorname{Ar}(14) / \mathrm{He}(30)$ & 29.91 & 1.21 & 29.28 & 0.63 & 2.11 \\
\hline
\end{tabular}



Figure 2: PSD of untreated and treated tungsten carbide powders at various plate powers

helium pycnometer. The $10 \mathrm{~cm}^{3}$ sample cup was used for density analysis of three samples to determine the average density. Particle size distribution (PSD) of all powders was determined using a Saturn DigiSizer II Analyzer.

\subsection{Phase composition}

The phase composition of the powders were determined by X-ray diffraction (XRD) using a Bruker D 8 Advance diffractometer equipped with $\mathrm{Cu} K \alpha(\lambda=0.15418 \mathrm{~nm})$ radiation source. Diffracted data was collected using a LynxEye position sensitive detector. The identification of the phases was done using ICDD's PDF4+ 2020 version database. The phase compositions were determined by Rietveld refinement.

\section{Results and discussions}

Metco 32C powder with a size fraction of $63-90 \mu \mathrm{m}$ was spheroidised at various plasma plate powers. Table 2 summarises the conditions and results from the spheroidisation process.

The evaporated powder mass after the spheroidisation process was relatively low, although as the plasma plate power increased, it resulted in an increase in powder evaporation.

Figure 2 shows the particle size distribution of the feed/ untreated powder and the spheroidised powders at various plate powers. From Figure 2 it was observed that the untreated feed powder had a wider particle size distribution as opposed to the spheroidised powders. The plasma treated powder had a narrower PSD when compared to the feed powder, while the distribution had shifted to a small particle size.
Table 3 shows the particle size distribution (PSD) results of all the Metco $32 \mathrm{C}$ powder as determined by light scattering.

From Table 3 it was deduced that the median of the tungsten carbide powder decreased after plasma treatment indicating a shift in the PSD to the smaller particle sizes. The decrease in the D90 after plasma treatment suggested a decrease in the amount of large particles while the amount of smaller particles remain similar before and after plasma treatment as shown by the D10.

Figure 3 depicts the SEM images of tungsten carbide powder before and after treatment. The magnification used for the BSE was $155 \mathrm{x}$.

From the images it is evident that as plate power was increased the number of spheroidised particles increased. At higher plate powers the powder particles are able to fully melt and ultimately spheroidise, as opposed to lower plate powers where the particles could be partly melted. These results were substantiated by the proven theory that the degree of spheroidisation is dependent on the operating conditions such as the carrier gas flow rate, powder feed rate, and the plasma plate power (Bissett \& Walt, 2017).
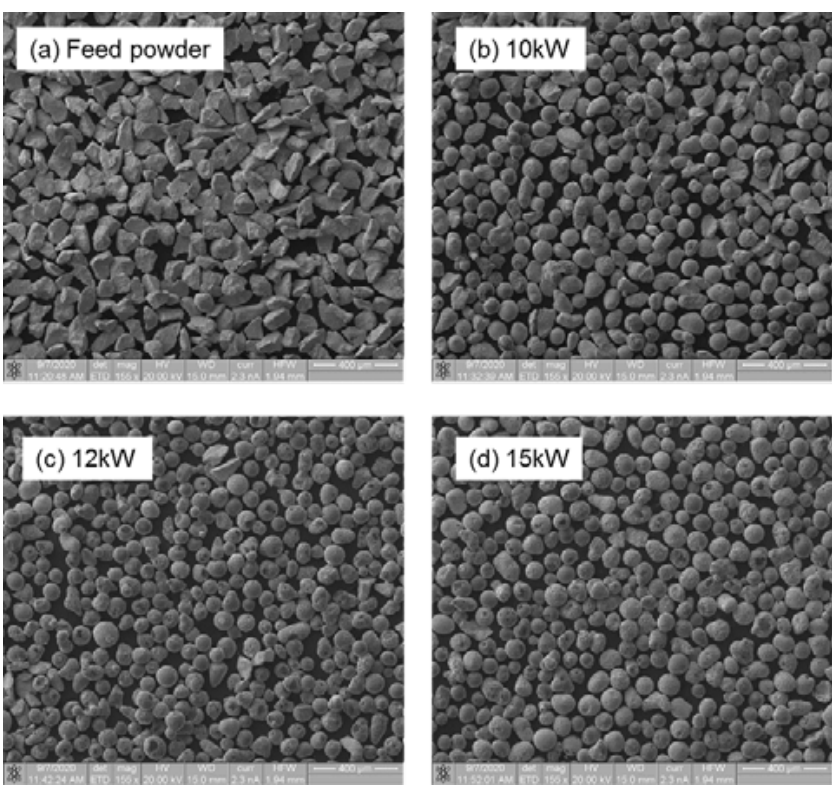

Figure 3: Backscatter SEM images at $155 \mathrm{x}$ magnification of the (a) WC $63-90 \mu \mathrm{m}$ feed powder and powders plasma treated at (b) $10 \mathrm{~kW}$, (c) $12 \mathrm{~kW}$ and (d) $15 \mathrm{~kW}$

Table 3: PSD of all Metco 32C powders as determined by light scattering

\begin{tabular}{ccccc}
\hline Plasma Condition $(\mathbf{k W})$ & Median $(\boldsymbol{D 5 0})(\boldsymbol{\mu m})$ & D90 & D10 & Standard deviation $(\boldsymbol{\mu m})$ \\
\hline Untreated & 100.150 & 153.409 & 68.766 & 2.232 \\
10 & 92.553 & 122.288 & 70.592 & 0.298 \\
12 & 92.258 & 126.088 & 69.245 & 0.400 \\
15 & 91.514 & 118.363 & 68.017 & 1.008 \\
\hline
\end{tabular}


Table 4: Average spheroidisation ratios of WC with PSD of 63-90 $\mu \mathrm{m}$ as determined by image processing software with spherical particles having circularity values of 0.85

\begin{tabular}{|c|c|c|c|c|c|c|}
\hline $\begin{array}{c}\text { Plasma } \\
\text { conditions }(\mathbf{k W})\end{array}$ & $\begin{array}{c}\text { Energy consumption } \\
(\mathbf{k g . h} / \mathbf{k W})\end{array}$ & $\begin{array}{c}\text { Spherical } \\
\text { particles (-) }\end{array}$ & $\begin{array}{c}\text { Irregular } \\
\text { particles (-) }\end{array}$ & $\begin{array}{c}\text { Spheroidisation } \\
\text { ratio }(\%)\end{array}$ & $\begin{array}{c}\text { Fraction of } \\
\text { evaporation }(\%)\end{array}$ & $\begin{array}{c}\text { Powder density } \\
\left(\mathrm{g} / \mathrm{cm}^{3}\right)\end{array}$ \\
\hline Untreated & - & 0 & 39 & 0 & - & 13.91 \\
\hline 10 & 4.37 & 10 & 30 & 25 & 1.3 & 12.79 \\
\hline 12 & 4.7 & 17 & 46 & 27 & 1.6 & 12.76 \\
\hline 15 & 12.4 & 10 & 10 & 50 & 2.11 & 12.65 \\
\hline
\end{tabular}

Table 4 shows the relation between energy input (or plasma power) on spheroidisation ratio, fraction of evaporation and the number of spherical and irregular particles. The spheroidisation ratio is defined as the percentage of spherical particles to the total number of particles in the treated product and is estimated by counting the spherical particles within a specific frame size of the micrograph. From both Table 4 and Figure 3 it is evident that at lower energy consumptions the number of spherical particles and the spheroidisation ratio were relatively low. This was also observed on the SEM images. By looking at the images, visually it was apparent that as the applied plate power was increased the shape of the particles had become more spherical. Although the fraction of evaporation seemingly increased as the energy consumption increased, the fraction of evaporations were relatively small for all plasma conditions which can be attributed to the high melting point of tungsten carbide. A slight decrease in the powder density was observed after plasma treatment. The reason for this is not known at this stage. It might be speculated that the presence of impurities might be responsible for this observation.

The X-ray diffraction profiles are given in Figure 4. For all the powders a mixed phase composition was revealed although the feed was only WC. The $\mathrm{WC}$ and $\mathrm{W}_{2} \mathrm{C}$ phases were present in all the powders but not at the same concentration. The WC phase composition decreased when the plasma power increased, while the $\mathrm{W}_{2} \mathrm{C}$ phase composition increased when the plasma operating power increased.

From Figure 4 it's evident that the XRD trend results of the feed/ untreated powder and plasma treated powder change in comparison were observed. There were 11 major $2 \theta$ peaks, 8 of these are WC peaks. The following peaks were identified as tungsten carbide: $31^{\circ}, 36^{\circ}, 48^{\circ}, 64^{\circ}, 75^{\circ}, 84^{\circ}, 99^{\circ}$ and $110^{\circ}$. These results conformed to diffraction peaks of standard tungsten carbide powder diffraction with a body-centred cubic (bcc) lattice structure. $\mathrm{W}_{2} \mathrm{C}$ compositions were identified at the following peaks: $38^{\circ}, 40^{\circ}$ and $52^{\circ}$.

The phase composition as determined by Rietveld refinement is shown in Table 5.

Table 5: Phase composition of the feed and plasma treated powders as determined from XRD analysis and Rietvield refinement

\begin{tabular}{ccc}
\hline Sample & \multicolumn{2}{c}{ Phase composition (\%) } \\
\hline & WC & $\mathbf{W}_{\mathbf{2}} \mathbf{C}$ \\
\hline Feed & 93 & 7 \\
$10 \mathrm{~kW}$ & 83 & 17 \\
$12 \mathrm{~kW}$ & 86 & 14 \\
$15 \mathrm{~kW}$ & 42 & 58 \\
\hline
\end{tabular}

Looking at Table 5 it's evident that there was a decrease in the concentration of the phase composition of $\mathrm{WC}$ to $\mathrm{W}_{2} \mathrm{C}$ when it was heated during the plasma spheroidisation process This phenomena is known as decarburization.

When carbon in the metal reacts with gases containing oxygen or hydrogen, the reaction results in the removal of carbon. Decarburization also occurs under inert condition, but at a much slower rate. This results in the removal of hard carbide phases which in turn softens the metal, primarily at the surfaces which are in contact with the decarburizing gas (Shvartsman, 1973).

\section{Conclusion}

From this study it was evident that when the tungsten carbide Metco 32C power was treated in the radio Tekna RF plasma spheroidization system at various conditions, the powder particles became more spherical. The spheroidisation ratio increased as the plate power increased. The spheroidisation ratio increased

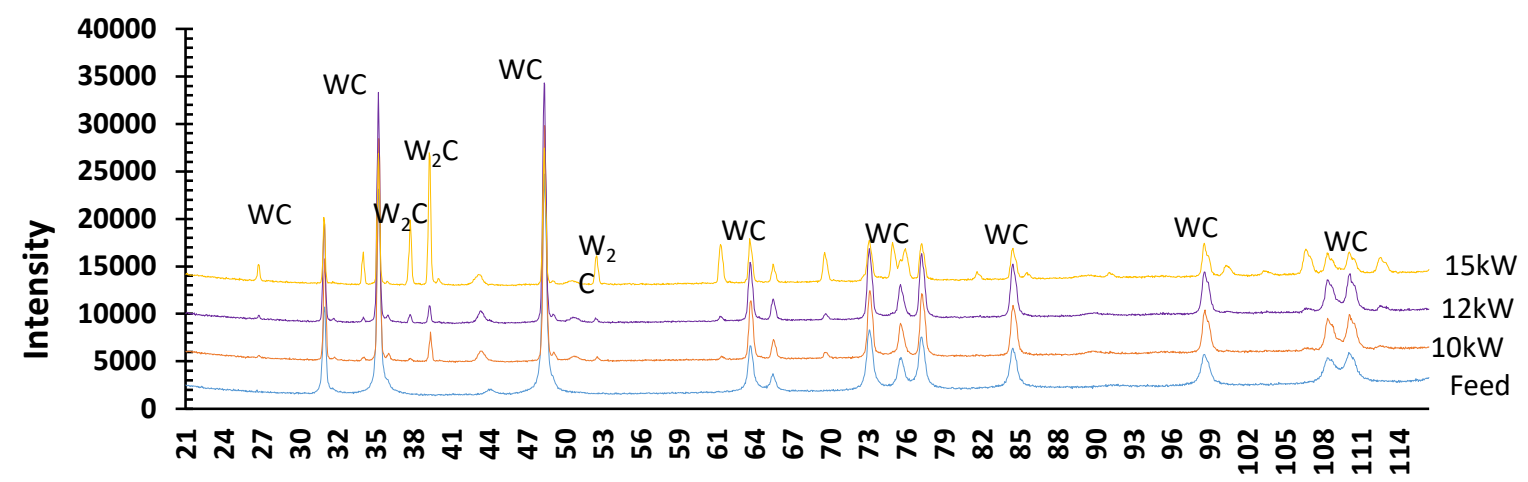

$2 \theta\left({ }^{\circ}\right)$

Figure 4: XRD graph of tungsten carbide metco $32 \mathrm{C}$ feed powder and treated powder with a size of $63-90 \mu \mathrm{m}$ 
between $25-50 \%$. The powder density decreased slightly after plasma treatment. This is contradictory to literature because as the spheroidisation ratio increases the density of the power should simultaneously increase.

The feed powder had a wider PSD as opposed to the treated powder. The treated powder were left skewed and depicted a unimodal PSD.

The XRD results depict that decarburization occurs because there is an increase in the $\mathrm{W}_{2} \mathrm{C}$ phase composition when the power of the RF plasma was increased. Thus resulting in the decrease of the WC phase composition as the plasma plate power increases.

\section{Acknowledgements}

The authors would like to acknowledge the Nuclear Materials Development Network (NMDN) of the Advanced Materials Initiative (AMI), funded by the Department of Science and Innovation (DSI) for the financial support in conducting this study. The South African Nuclear Energy Corporation (SOC) Ltd (Necsa) is acknowledged for their financial support. The following Necsa personnel are thanked for their contributions: Dr. SJ Lotter and Mr. TP Ntsoane for the SEM and XRD analysis respectively and Mr. MM Makhofane and Mr. PC Smith for the plasma experiments. Mrs. M Theron from the CSIR National Laser Centre is also thanked for supplying tungsten carbide powder which was used for experimentation.

\section{References}

1. Bissett, H. \& Walt, I. v. d., 2017. Metal and alloy spheroidisation for the Advanced Metals Initiative of South Africa, using high-temperature radiofrequency plasma. Journal of the Southern African Institute of Mining and Metallurgy, 117(10), pp. 975-980.

2. Committee, A., 2020. ASTM International. [Online] Available at: https://www.astm.org/COMMITTEE/F42.htm [Accessed 1811 2020].

3. Gebler, M., Uiterkamp, A. S. \& Visser, C., 2014. A global sustainability perspective on 3D printing technologies. Energy Policy, 74(C), pp. 158-167.
4. Gao, S., Chen, S., Chen, K., Ji, Z. \& Chen, J., 2017. A long pulse width and high extraction rate arc plasma electron beam source. Instruments and Experimental Techniques,, 60(5), pp. 705-709.

5. Haehn, R., Luederitz, E., Sattelberger, S. \& Retelsdorf, H., 1986. New process for the production of cast tungsten carbide. Metal Powder Report, 41(12), pp. 887-890.

6. Hendrixson, S., 2016. AM in depth education. [Online] Available at: https://www.additivemanufacturing.media/blog/post/plasmaspheroidization-improves-quality-of-metal-powder-for-am [Accessed 1911 2020].

7. Ji-Gui, C., Laima, L., Qiu, X., Xiao-Yue, T., Xiang, Z., Xiao-Yong, Z., \& Yu-Cheng, 2020. Preparation Technology of Ultra-Fine Tungsten Carbide Powders: An Overview. Frontiers in Materials , Volume 7, pp. 94-96.

8. Kriewall, C. \& Newkirk, J., 2019. Plasma Spheroidization of Vitreloy 106A Bulk Metallic Glass Powder. Metall Mater Trans, Volume 50 A, p. 4791-4797.

9. Liu, B., Wildman, R., Tuck, C., Ashcroft, I. \& RHague., 2011. Investigation of the effect of particle size distribution on processing parameters optimiation in selective laser melting process. Loughborough : Additive Manufacturing Research Group, Loughborough University .

10. Lu, X., Zhu, L. \& Zhang, B., 2012. Simulation of flow field and particle trajectory of radio frequency inductively coupled plasma spheroidization. Computer Material Science, Volume 65, p. 13-18.

11. Neely, A., 2008. Exploring the financial consequences of the servitisation of manufacturing. Operations Management Research, 1(2), pp. 103-118.

12. Oerlikon, 2017. Oerlikon. [Online] Available at: https://www.oerlikon. com/ecomaXL/files oerlikon_BRO-0001.17_TS_MaterialGuide_ EN.pdf [Accessed 17 March 2021].

13. Shvartsman, L., 1973. Decarburization: The Great Soviet Encyclopedia (Print). 3 ed. New York: Macmillan.

14. Sutton, A., Kriewal, C., Leu, M. \& Newkirk, J., 2016.. Powders for Additive Manufacturing Processes: Characterization Techniques and Effects on Part Properties," Proceedings of the 27th Solid Freeform Fabrication Symposium. Austin, Laboratory for Freeform Fabrication.

15. Tong, J., Lu, X., Liu, C., Wang, L.,\& Qu, X., 2015. Fabrication of micro-fine spherical high $\mathrm{Nb}$ containing TiAl alloy powder based on reaction synthesis and RF plasma spheroidization. Powder Technology, 283, pp. 9-15.

16. Wahll, M., Orsdel, J. V. \& Fischer, R., 2014. Spheroidisation of irregularly shaped metal powders. Powder Metallurgy, 4(8), pp. 48-64.

17. Wohler, T., 2014. Wohler report, OakRidge: Wohlers Associates, Inc; 